Condition $\mathrm{a}=$ reference condition

Condition $b=$ increase enzyme $\mathrm{E}$
Transcriptional control

$$
\mathrm{S}
$$

$\Phi_{\mathrm{a}}$

$$
\text { S }
$$

$\Phi_{\mathrm{b}}>\Phi_{\mathrm{a}}$

$\Phi_{\mathrm{c}}=\Phi_{\mathrm{a}}$

S

$\Phi_{\mathrm{d}}=\Phi_{\mathrm{b}}$

Metabolic control

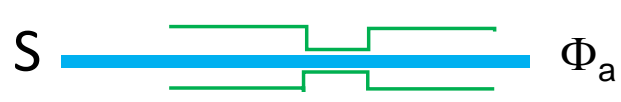

$\mathrm{S}$

$\mathrm{S}$

S

S
$\Phi_{\mathrm{b}}=\Phi_{\mathrm{a}}$

\section{Combined control}

$\Phi_{\mathrm{c}}>\Phi_{\mathrm{a}}$

$\Phi_{\mathrm{d}}=\Phi_{\mathrm{c}}$
S

S

S

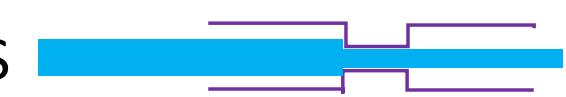

$\Phi_{\mathrm{a}}$ $\Phi_{\mathrm{b}}>\Phi_{\mathrm{a}}$

s

$\Phi_{\mathrm{c}}=\Phi_{\mathrm{a}}$

S 